\title{
Analysis of Types And Costs of Drugs Used For 7 Days Before Death of Terminal Cancer Patients Hospitalized In Hospice And General Wards.
}

Kichul Kim ( $\sim$ kkchuli@naver.com )

Seoul St. Mary's Hospital https://orcid.org/0000-0002-6001-0724

\section{Chul-Min Kim}

Seoul Seongmo Byeongwon: Seoul Saint Mary's Hospital

\section{Jeongran $\mathrm{Ra}$}

Seoul Seongmo Byeongwon: Seoul Saint Mary's Hospital

\section{Yula Kim}

Seoul Seongmo Byeongwon: Seoul Saint Mary's Hospital

Ahreum Park

Seoul Seongmo Byeongwon: Seoul Saint Mary's Hospital

\section{Research Article}

Keywords: hospice, cost, types of medications, end of life

Posted Date: June 3rd, 2021

DOI: https://doi.org/10.21203/rs.3.rs-454444/v1

License: (c) (i) This work is licensed under a Creative Commons Attribution 4.0 International License. Read Full License 


\section{Abstract}

1) Purpose

The need for hospice palliative care continues to grow as the number of deaths from cancer increases with increasing interest in and need for the management of end stage cancer patients. We conducted this study to determine differences in quantity and cost of drugs used by end-stage cancer patients who were hospitalized in general wards or hospice wards for 7 days before death.

\section{2) Methods}

Among patients who died in the hospice ward or the general ward of a university hospital in a metropolitan city (Seoul) from January 2016 to September 2019, patients aged over 18 years with a hospital stay of 8 days or more were selected. A total of 526 patients were selected, including 290 from hospice wards and 236 from general wards.

3) Results

Numbers of PO, injections, and fluid, but not opioids, used in the hospice ward were significantly lower than those in the general ward. Cost of PO, injections, fluid, and total costs were significantly lower in the hospice ward than in the general ward. In the case of opioids, the cost was higher for the hospice ward. Total costs including all drug costs in the hospice ward were significantly lower than those in the general ward.

4) Conclusion

Caring for people with terminal cancer in a hospice can lower costs and increase satisfaction for dying patients. Reducing the proportion of patients caring for terminal cancer in general wards and increasing access to hospice services can address health insurance deficits and exhaustion.

\section{Introduction}

The number of deaths from cancer in Republic of Korea is increasing every year. The mortality rate was 158.2 per 100,000 people in 2019, an increase of 3.9 per 100,000 people from 2018 and an increase of 17.7 per 100,000 people from 2009. The cancer mortality rate in 2019 was 36.2 per 100,000 people for lung cancer, 20.6 per 100,000 people for liver cancer, 17.5 per 100,000 people for colon cancer, 14.9 per 100,000 people for stomach cancer, and 12.5 per 100,000 people for pancreatic cancer [1].

The number of deaths from cancer is steadily increasing, leading to increased interest in and desire for managing end-stage cancer patients, further raising the need for hospice palliative care. Hospice palliative medicine is for end-stage patients who are expected to die within a few months. It not only covers physical symptoms, but also covers mental, psychological, spiritual, and social areas through pain and symptom control rather than treatment [2]. Providing hospice palliative care services to cancer patients will allow them to manage their terminal illness, which may improve their quality of life. The patient's family will have the opportunity to see a peaceful patient who is psychologically stable so that they can have a happy time with the patient. To meet expectations and interests in hospice palliative medicine, the government is contributing to the development of a hospice palliative medicine system.

With the enactment of Cancer Management Act in 2003, the term of 'palliative care' was introduced in 2005 and financial support was given to 15 medical institutions for providing hospice palliative care [3]. In July 2015, all institutions were expanded to have a compound payment method of daily flat rate and fee-for-service systems. The health insurance system was implemented only for hospice palliative care institutions [4]. However, not all terminal cancer patients use a hospice service. In fact, there are more cases of death in general wards than in hospice wards. The number of hospice service users in 2018 was 18,091 out of 79,153 cancer death patients, with a utilization rate of $22.9 \%$ [5]. 
According to statistical analysis of total medical expenses of health insurance released by the Statistics Korea, drug cost is increasing. It was $\$ 15,428.7$ billion in $2016, W 16,209.8$ billion in $2017, W 17,866.9$ billion in 2018 , and $W 19.338 .8$ billion in 2019 [6]. In general wards, near-death patients are continuously treated with various drugs. However, late-stage drug administration needs to be reconsidered since they have more side effects than beneficial effects. When death is imminent, effects of drugs can be delayed, the risk of side effects can be increased as function of organ changes. In addition, treatment goals can be changed, which can lead to inappropriate drug administration [7].

Yeom et al. [8] have compared medical costs by medical institutions for the last week of terminally ill patients and revealed that the hospice ward has lower cost than the general ward. Son et al. [9] have analyzed total medical expenses of patients four weeks before death and found that those who have been receiving hospice care for one week are lower than those of patients who die after they are treated in a general ward for the same disease. Although previous studies have revealed differences in total medical costs between hospice wards and general wards [8-9], differences in costs of drugs alone have not been reported yet. Therefore, the objective of this study was to determine the difference in quantity and cost of drugs used by end-stage cancer patients in general and hospice wards for 7 days before death.

\section{Subjects And Methods}

\section{Subjects}

Subjects of this study were selected from patients who died in hospice and general wards of the Catholic University of Korea, Seoul St. Mary's Hospital from January 2016 to September 2019. In particular, patients aged 18 years or older with a hospitalization period of 8 days or more (excluding the day when the transfer was changed to the hospitalization date) were selected. They were divided into patients in the hospital ward and those in the general ward. Subjects of this study were endstage cancer patients. Patients who received anticancer drugs or targeted therapies at 15 days before the end of life including the last day of life were excluded. The hospice ward had 290 people and the general ward had 236 people. Thus, a total of 526 people were selected as final subjects of this study. This study was approved by the IRB (Institutional Review Board) of the Catholic University of Korea. Seoul St. Mary's Hospital (project number KC19RESI0451).

\section{Chart review}

This was a retrograde comparative analysis study of three drug types (PO (per oral), injections, fluid and opioids) and costs used during 7 days prior to death based on chart reviews of patients in general and hospice wards admitted to The Catholic University of Korea, Seoul St. Mary's Hospital. Five types of cancer were selected for comparative analysis of patients in hospice and general wards. These five types of cancer selected were: lung cancer, liver cancer (including biliary tract), colon cancer (including colon and rectum), gastric cancer, and pancreatic cancer known to have high mortality rates.

Patient demographics (gender, age at the time of death), date of admission, date of death, cancer type, and data (drug code, generic name of General Hospital in Seoul, date of administration, dosage) of all drugs used during 7 days before death were collected. All drug data collected were classified into three groups: PO, injections, fluid and opioids.

Prices of all collected drugs were calculated with reference to drug prices of the Catholic University of Korea. Seoul St. Mary's Hospital where the patient was hospitalized and the drug integrated information system. For comparative analysis of hospice ward and general ward, the sum and cost of the number of drugs used for each patient's 7th, 6th, 5th, 4th, 3rd, 2nd, $1 \mathrm{st}$, and death day were calculated and recorded. The day of death was excluded because the time of death was different for each patient that made it impossible to calculate and record drug types and costs with the same standard. Microsoft Excel 2016 was used for accurate calculations of collected data.

\section{Statistical analysis}


Subjects were divided into lung cancer, liver cancer (including biliary tract), colon cancer (including colon and rectum), gastric cancer, and pancreatic cancer patients among premortal patients admitted to hospice and general wards. Differences in drug usage and cost were analyzed in terms of cancer types, day before death, and two wards using SAS System for Windows V 9.4 software. Descriptive statistics Analysis, Frequency analysis, Repeated measures ANOVA, Repeated measures ANCOVA, Wilcoxon rank sum test, and ANOVA / Kruskal-Wallis Test T-test analysis were performed to check whether there were significant differences between the two groups.

\section{Results}

1. Clinical characteristics of subjects.

There were 290 patients in the hospice ward and 236 patients in the general ward. The total number of patients included in this study was 526. Among patients in the hospice ward, there were 167 (57.59\%) men and 123 (42.41\%) women. Regarding the number of hospice ward patients according to cancer type, there were 53 (18.28\%) patients with gastric cancer, 62 (21.38\%) with lung cancer, 55 (18.97\%) with colon cancer, 51 (17.59\%) with hepatobiliary cancer, and 69 (23.70\%) with pancreatic cancer. As for the number of hospice ward patients according to age, there were 11 (3.79\%) patients under the age of $50,30(10.34 \%)$ in their 50s, 67 (23.10\%) in their 60s, 97 (33.45\%) in their 70s, and $85(29.31 \%)$ over 80 years old. Regarding the number of deaths of hospice ward patients according to year, it was $80(27.29 \%)$ in 2016, 78 (26.9\%) in 2017 , $74(25.52 \%)$ in 2018 , and $58(20 \%)$ in 2019.

Among general ward patients, there were 157 (66.53\%) men and 79 (33.4\%) women. As for cancer types among general ward patients, there were 33 (13.98\%) with gastric cancer, 68 (28.81\%) with lung cancer, 55 (23.31\%) with colon cancer, 42 (17.8\%) with hepatobiliary cancer, and $38(16.1 \%)$ with pancreatic cancer. Regarding their ages, there were $17(7.20 \%)$ under the age of 50, $45(19.07 \%)$ in their 50s, $63(26.69 \%)$ in their 60 s, and $79(33.47 \%)$ in their 70 s, and $32(13.56 \%)$ over 80 years old. Regarding the year of death, there were 59 (27.29\%) deaths in 2016, 61 (26.9\%) in 2017, 80 (25.52\%) in 2018, and 36 (20\%) in 2019 (Table 1).

Table 1. Clinical characteristics of study subjects $(n=526)$ 


\begin{tabular}{|c|c|c|c|c|}
\hline \multicolumn{2}{|l|}{ Categories } & \multirow{2}{*}{$\begin{array}{l}\text { Hospice Ward } \\
(\mathbf{n = 2 9 0 )} \\
167(57.59 \%)\end{array}$} & \multirow{2}{*}{$\begin{array}{l}\text { General Ward } \\
(n=236) \\
157(66.53 \%)\end{array}$} & \multirow{2}{*}{$\begin{array}{l}\text { Total } \\
(\mathbf{n = 5 2 6 )} \\
324(61.6 \%)\end{array}$} \\
\hline Sex & Male & & & \\
\hline & Female & $123(42.41 \%)$ & 79(33.47\%) & 202(38.4\%) \\
\hline \multirow[t]{5}{*}{ Cancer } & Stomach & $53(18.28 \%)$ & $33(13.98 \%)$ & $86(16.35 \%)$ \\
\hline & Lung & $62(21.38 \%)$ & $68(28.81 \%)$ & $130(24.71 \%)$ \\
\hline & Colon & $55(18.97 \%)$ & $55(23.31 \%)$ & $110(20.91 \%)$ \\
\hline & Hepatobiliary & $51(17.59 \%)$ & $42(17.8 \%)$ & $93(17.68 \%)$ \\
\hline & Pancreas & 69(23.79\%) & $38(16.1 \%)$ & $107(20.34 \%)$ \\
\hline \multirow[t]{5}{*}{ Age (year) } & $<50$ & 11(3.79\%) & 17(7.20\%) & $28(5.32 \%)$ \\
\hline & $50 \sim 59$ & $30(10.34 \%)$ & $45(19.07 \%)$ & $75(14.26 \%)$ \\
\hline & $60 \sim 69$ & $67(23.10 \%)$ & 63(26.69\%) & $130(24.71 \%)$ \\
\hline & $70 \sim 79$ & $97(33.45 \%)$ & 79(33.47\%) & $176(33.46 \%)$ \\
\hline & $>80$ & $85(29.31 \%)$ & $32(13.56 \%)$ & $117(22.24 \%)$ \\
\hline \multirow[t]{4}{*}{ Year of death } & 2016 & $80(27.59 \%)$ & $59(25 \%)$ & $139(26.43 \%)$ \\
\hline & 2017 & $78(26.9 \%)$ & $61(25.85 \%)$ & $139(26.43 \%)$ \\
\hline & 2018 & $74(25.52 \%)$ & $80(33.9 \%)$ & $154(29.28 \%)$ \\
\hline & 2019.9 & $58(20 \%)$ & $36(15.25 \%)$ & $94(17.87 \%)$ \\
\hline
\end{tabular}

2. Number and cost of medications in hospice and general wards for 7 days before death

Numbers of PO, injections, fluids and opioids used in the hospice ward were less than those in the general ward. The difference in the usage of PO was the largest for all drug types (PO, injections, fluid and opioids), while the difference in the usage of opioids was the least. The total amount of drug usages in the general ward was higher than that in the hospice ward. Only in the case of opioids, the difference between the two groups was not significant $(p=0.087)$. Total amount and costs of drugs showed significant difference (both $p<0.001$ ). In terms of costs, the total cost and costs of all individual drugs (PO, injections, and fluids) were lower in the hospice ward than those in the general ward. However, the cost of opioids in the hospice ward was higher than that in the general ward. Fluid showed the largest difference between the hospice ward and the general ward. Each drug cost and total costs were also significantly different between the two wards (both $p<0.001$, Fig. 1)

3. Distribution of medication cost depending on types of drugs in hospice ward and general ward for 7 days before death

The total cost of drugs on average was $\$ 171,853$ in the hospice ward and $\$ 1,146,885$ in the general ward. Thus, the total cost was 6.67 times higher in the general ward than in the hospice ward. Depending on types of drugs, differences were as follows. The percentage of PO cost in the total was the same at $2 \%$ for both wards. However, the proportion of opioids usage was $23 \%$ in the hospice ward, which was significantly higher than that (2\%) in the general ward. The proportion of usage of fluids was $79 \%$ in the general ward and $55 \%$ in the hospice ward, showing a $22 \%$ difference. The proportion of usage of opioids was $94.8 \%$ for hospice patients and $81.7 \%$ for general ward patients (Fig. 2).

4. Changes in number and cost of medications in hospice and general wards for 7 days before death 
In the hospice ward, there were significant decreases in the number of drugs and cost from the 7th day before the death to the last day before death ( $p=0.0464$ and $p<0.001$, respectively). In the general ward, there was no significant change in the number of drugs or cost from the 7 th day before the death to the last day before the death (both $p>0.05$, Fig. 3).

\section{Comparison of costs in hospice and general wards according to cancer type}

In the case of colon cancer, the average cost was $\$ 161,246$ for the hospice ward and $\$ 1,337,978$ for the general ward, showing the largest difference of $\$ 1,176,731$. In the case of lung cancer, the average cost was $\$ 180,967$ for the hospice ward and $\$ 1,130,701$ for the general ward, showing the second-largest difference of $\$ 949,733$. For pancreatic cancer, the average cost was $\$ 178,848$ for the hospice ward and $W 1,014,040$ for the general ward, showing the smallest cost difference of $\$ 835,191$ (Table 2).

Table 2

Comparison of costs in hospice ward and general ward according to cancer type

\begin{tabular}{|c|c|c|c|}
\hline Cancer type & Hospice Ward & General Ward & Difference \\
\hline Stomach & $W 175,071$ & $\$ 1,075,034$ & W899,963 \\
\hline Lung & W180,967 & $W 1,130,701$ & W949,733 \\
\hline Colon & $W 161,246$ & W1,337,978 & $W 1,176,731$ \\
\hline Hepatobiliary & $\$ 159,404$ & $\# 1,099,496$ & \#940,092 \\
\hline Pancreas & W178,848 & $\$ 1,014,040$ & \#35,191 \\
\hline
\end{tabular}

\section{Discussion}

It was found that medical expenses for one month before death were 2.5 times the monthly average of medical expenses for the year before the death. Half (50\%) of medical expenses before death of all cancer patients were spent in three months before death. As medical technology advances, various treatments and more care services are provided to patients when death approaches. However, due to the lack of facilities to properly take care of end-stage patients in peace, the general ward is used to provide continuous medical services to patients [10].

Excessive medical expenses before death may increase further in Republic of Korea, which is entering a super-aged society. Health insurance finance recorded a deficit of $\$ 177.8$ billion in 2018. Its cumulative reserve is decreasing to $\$ 20,596$ billion. It is expected to be exhausted by 2025. If policies to strengthen security are continuously promoted, such health insurance deficit will further increase year by year and the cumulative reserve fund will decrease accordingly, thus further increasing financial depletion [11].

According to results of this study, the cost of drugs used during 7 days before death in the general ward was 6.67 times higher than that in the hospice ward. In the case of cancer patients, the use of hospice services had steadily increased from $7.3 \%$ in 2008 to $20.9 \%$ in 2018. However, many cancer patients are still dying in general wards rather than in hospice wards [12]. Financial resources of the hospice ward consist of national health insurance and national support funds. It is not easy to reduce the cost of drugs used in general wards. Reducing the proportion of patients with terminal cancer care in general wards and increasing the utilization rate of hospice services can be an alternative solution for the problem of health insurance deficit and depletion.

Opioids accounted for $23 \%$ of drug costs in the hospice ward, higher than $2 \%$ in the general ward. It was also found that $94.8 \%$ of all hospice patients used narcotics while only $81.7 \%$ of those in general wards used them. The reason for using a 
lot of opioids was to ensure that the patient was comfortable and pain-free in the hospice ward. In hospice wards, opioids were used to control and treat pain. If necessary, drugs were sufficiently used. For hospice patients in 2017, the mean pain measured by NRS was reduced from 3.2 to 2.2 , indicating a significant $(p<0.001)$ pain relief [13]. Symptom control was well regulated in the hospice ward as shown in results measured by NRS.

In the general ward, various drugs were used to control pain. However, in the hospice ward, effective injections were mainly used to control pain. Although the number of drug types used in the hospice ward was smaller, higher doses might have resulted in more costs. In the hospice ward, even if the patient was unconscious at the end of life, the pain control was actively implemented so that the patient could spend a comfortable end of life. In the hospice ward, drugs were not simply reduced or restricted for end-of-life patients. Because the hospice ward was concerned about side effects such as blood pressure, decreased breathing, and decreased consciousness. Recognizing these side effects, appropriate medications were selected and used for patients, allowing them to maintain comfort without feeling pain.

Different from findings for the general ward, the number of drugs and cost decreased significantly in the hospice ward from the 7th day before death to the last day before death. This was because unnecessary drugs were not used as death approached. Ducan et al. have studied Medicare Limited Data Set 2015-2016 and found that the average hospitalization cost is US\$ 638 for 4-7 days before death and US\$5,983 for 1-3 days before the death, an increase of about 10 times. However, the hospice ward was covered by a comprehensive compensation system. Its cost was US\$230.74 per day, resulting in lower hospitalization costs for patients receiving end-of-life care in a hospice ward than in general ward. [14].

Reasons for lower costs in hospice ward than in general ward are as follows. First of all, the hospice ward has different predictions of death from the general ward. Looking at drug use in general wards, PO, fluids, antibiotics, and so on are being used continuously until the end of life. In the hospice ward, end-of-life patients are frequently contacted. If the patient is predicted to die within a few days, Dying Care Pathway [15] is applied. If Dying Care Pathway is applied, the hospice ward will regulate fluid supply to a minimum volume. The reason is that supplying excessive fluids to end-of-life patients does not extend their survival period[16-17]. In addition, side effects due to fluid imbalance or increased bronchial secretion due to fluid supply are increased[18]. Instead, drugs that mainly control accompanying symptoms are provided. If the drug used for the patient does not help or can harm the patient's symptoms, the usage of such drug is discontinued. However, in general wards, it is difficult to frequently contact end-of-life patients. Thus, evaluation is not properly performed. Since the patient is not judged to be in a terminal stage, the drug will be used continuously without reducing the dose. It can be the main cause of high cost by continuing to use drugs such as excessive fluids, injections, antibiotics, oral drugs, and so on, even right before death .

Secondly, in the hospice ward, Physician Order for Life Sustaining Treatment (POLST) and Advance Directives (AD) are prepared and a high proportion of patients are hospitalized with agreement for POLST and AD. When a patient enters the terminal stage of life, it is easy to proceed according to the POLST. Guardians also understand and prepare for the end of life so that consent for drug reduction can be easily obtained. In general wards, the proportion of patients who do not reveal their intention to discontinue life-prolonging treatment is high. Because there are parents who wish to continue life-prolonging treatment, it is impossible to easily reduce the dose of the drug. As more drugs are used and the number of drugs is increased, costs are also increased.

There were 36.2 deaths per 100,000 people due to lung cancer, 20.6 deaths per 100,000 people due to liver cancer, and 17.5 deaths per 100,000 people due to colon cancer in Republic of Korea [1], accounting for $46.9 \%$ of all cancer deaths. If these lung cancer, colon cancer, and liver cancer patients in their terminal stages use hospice wards instead of general wards, money could be saved. Republic of Korea's dying quality (palliative care) ranking had increased from the 32nd out of 40 countries in 2010 to the 18th out of 80 countries in 2015 [19]. In the 2017 satisfaction survey of bereavement families, the satisfaction rate for hospice was $97 \%$, which was higher than the satisfaction rate of $69 \%$ for cancer treatment institutions used before enrolling in hospice [20]. This suggests that hospice is giving patients a comfortable and dignified death and giving guardians satisfaction. 
The number of hospitalized hospice institutions had increased from 81 in 2017 to 84 in 2018, 88 in 2019, and 86 in 2020 and 2021 [5]. To increase hospice utilization rate by terminal cancer patients, it is necessary to increase the number of hospice institutions. However, not all institutions are expanding due to low remuneration based on a daily flat rate system. Considering the difference in drug costs between the hospice ward and the general ward based on results of this study, expanding support in a way that preserves more daily flat rate in the hospice ward will result in an increase in the number of inpatient hospice institutions. It may be a good idea to develop and implement incentive policy that allows patients with terminal cancer, which seriously differs in cost, to be cared for in a hospice ward with a higher priority [21].

Since this study analyzed patients who died in the hospice ward and general ward of one metropolitan university hospital, results of this study could not be generalized for all hospitals. In addition, names of some drugs might have changed depending on the year. Some drug prices might also differ depending on the year. In this study, the comparison of cost was calculated only by the type and cost of the drug. In the case of general wards that do not provide life-sustaining treatment other than drugs, additional calculation of the cost of CPR and ventilator treatment might show more differences. Since this study only compared drug costs, it was impossible to accurately compare actual expenses. More research will be needed in the future.

In this study, the current status of differences in drug types and costs in hospice and general ward was determined. The government plans to increase hospice utilization rate of terminal cancer patients to 30\% by 2022 [19]. Patients at the end of their lives absolutely need care to end their lives by respecting their right of self-determination while having less physical peace and less psychological pain. A hospice ward plays a very important part in national and social costs. It can lead to lower cost but higher quality alternatives for dying patients. Thus, it is necessary to create a healthy policy and environment to promote the use of hospice through more research in the future.

\section{Declarations}

Funding: This research did not receive any specific grant from funding agencies in the public, commercial, or not for profit sectors.

Conflicts of interest/Competing interests: The authors declare that they have no conflict of interest.

Availability of data and material: The datasets generated and/or analyzed during the current study are available from the corresponding author on reasonable request

Code availability: N/A.

Authors' contributions: N/A

Ethics approval: This study was approved by the IRB (Institutional Review Board) of the Catholic University of Korea. Seoul St. Mary's Hospital (project number KC19RESI0451)

Consent to participate: N/A

Consent for publication: All the coauthors approve the manuscript.

\section{References}

1. Statistics Korea. Cause of death. Statistics Korea; 2019. Available from: http://kostat.go.kr/portal/korea/kor_nw/1/6/2/index.board? bmode=read\&bSeq=\&aSeq=385219\&pageNo=1\&rowNum=10\&navCount=10\&currPg=\&searchlnfo=\&sTarget=title\&sTxt=

2. Francisca Rego and Rui, The interface between psychology and spirituality in palliative care, Journal of Health Psychology ; 2019, Vol. 24(3) 279-287. https://doi.org/10.1177/1359105316664138

Page $8 / 11$ 
3. Chang Gon Kim, The History of Hospice and Palliative Care in Korea, Journal of Hospice and Palliative Care, 2019; 22(1): 1-7. https://doi.org/10.14475/kjhpc.2019.22.1.1

4. Mun Nam Lim, Seong Woo Choi, So Yeon Ryu, Mi Ah Han, Changes in the Medical Cost and Practice Pattern according to the Implementation of per Diem Payment in Hospice Palliative Care, Health Policy and Management; 2019, Vol.29 No.1, 40-48. https://doi.org/10.4332/KJHPA.2019.29.1.40

5. hospice.go.kr [Internet].Seoul: National Cancer Center, National Hospice Center; c2008-2018. [cited 2021 Jan 1]. Available from: https://hospice.go.kr/pain/stat.do

6. Korean Statistical Information Service. Drug costs compared to total medical expenses for health insurance. Available from https://kosis.kr/statHtml/statHtml.do?orgld=354\&tblld=DT_354004N_001

7. Jimmy J Arevalo, Eric CT Geijteman, Bregje AA Huisman, Marianne K Dees, Wouter WA. Zuurmond, Lia van Zuylen, et al. Medication Use in the Last Days of Life in Hospital, Hospice, and Home Settings in the Netherlands. Journal of Palliative Medicine 2018; 21(2):149-155.

8. Chang Hwan Yeom, Youn Seon Choi, Hye Ree Lee, Jae Yong Shim, Young Seon Hong, Wha Sook Choe, et al. The comparison of the medical costs and quality of life in terminal cancer patients by the types of medical facilities. J Korean Acad Fam med 2000; 21:332-343. https://www.kjfm.or.kr/upload/pdf/Kafm021-03-04.pdf

9. Choi Kui Son, You Chang Hoon, Lee Kyung Hee, Kim Chang Yup, Heo Dae Seog, Yon Young Ho : Comparison of Medical Care Cost between Hospice Care and Conventional Care in the Last Year of life. Health Policy and Management ; 2005, Vol.15(2) 1-15. https://doi.org/10.4332/KJHPA.2005.15.2.001

10. Kyu Sik Lee, National Health Insurance Service, Efficient management plan for elderly medical expenses in preparation for an aging society, 2017; 62-64, Available from: http://www.alio.go.kr/mobile/research_view.do? pageNo=1\&idx=2252837\&search_opt=\&search_text=

11. Jae Hong Joo, Sung-In Jang, Eun-Cheol Park, Korea National Health Insurance Service Financial Status and Prospect, Health Policy and Management Vol.30 No.2, 192-198. https://doi.org/10.4332/KJHPA.2020.30.2.192

12. www.ncc.re.kr [Internet].Seoul: National Cancer Center; c2008-2020. [cited 2020 Jun 30]. Available from: https://www.ncc.re.kr/main.ncc?uri=manage01_8

13. Ministry of Health and Welfare, National Cancer Center, 2017 Hospice and Palliative Care status, 2017; 27-28. Available from: http://www.mohw.go.kr/upload/viewer/skin/doc.html?

fn=1551314433886_20190228094035.pdf\&rs=/upload/viewer/result/202105/

14. Ian Duncan, FSA, FIA, FCIA, FCA, CSPA, MAAA, Tamim Ahmed, PhD, MBA, Henry Dove, PhD, MBA, and Terri L. Maxwell, PhD, APRN, et al. Medicare Cost at End of Life. American Journal of Hospice \& Palliative Medicin 2019, Vol. 36(8) 705710

15. Ellershaw J, wilkinson S. Care of the dying: A pathway to excellence. New York: Oxford Universiry Press, 2003.

16. Cerchietti L, Navigante A, Sauri A, Palazzo F. Hypodermoclysis for control of dehydration in terminal-stage cancer. International journal of palliative nursing. 2000;6(8):370-374.

17. Waller A, Hershkowitz M, Adunsky A. The effect of intravenous fluid infusion on blood and urine parameters of hydration and on state of consciousness in terminal cancer patients. The American journal of hospice \& palliative care. 1994;11(6):22-27.

18. Morita T, Hyodo I, Yoshimi T, et al. Association between hydration volume and symptoms in terminally ill cancer patients with abdominal malignancies. Annals of oncology : official journal of the European Society for Medical Oncology. 2005;16(4):640-647

19. Ministry of Health and Welfare, The 1st Hospice and Palliative Care Comprehensive Plan (2019 2023); 2019; 5, 31, Epup 2019 Jul 24, https://www.korea.kr/archive/expDocView.do?docld=38541 
20. www.mohw.go.kr [Internet].Seoul: Ministry of Health and Welfare; c2017. [cited 2019 Mar 04]. Available from: http://www.mohw.go.kr/react/al/sal0301vw.jsp?PAR_MENU_ID=04\&MENU_ID=0403\&CONT_SEQ=347917\&page=1

21. Byung Kyu Park, Ilsan Hospital Institute of Health Insurance \& Clinical Research, Analysis of Inpatient Hospice Use and Effects of Terminal Cancer Patients After Health Insurance Application, 2018; 66-68 http://www.alio.go.kr/popSusiViewB1040.do?seq=2019082301885279

\section{Figures}

\section{Number}

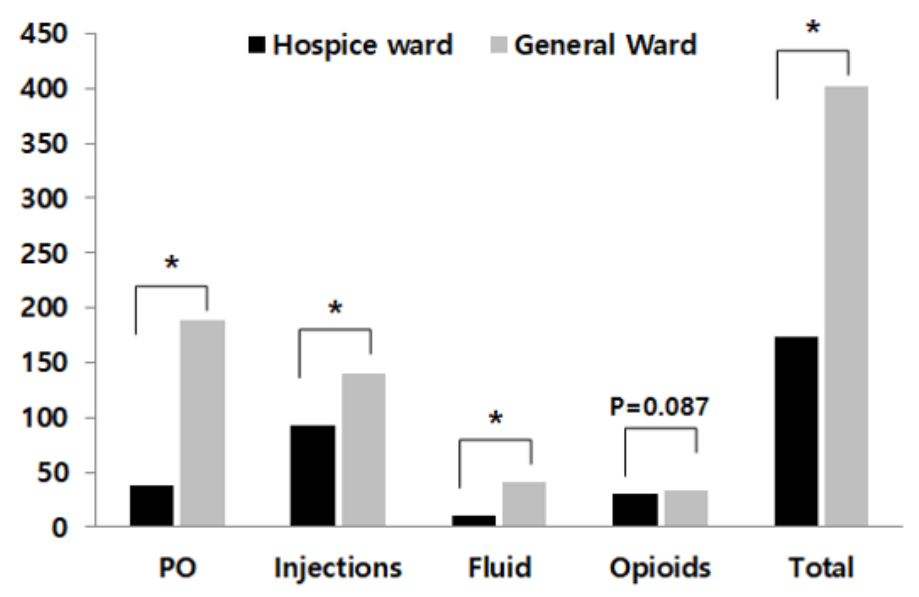

\section{Cost}

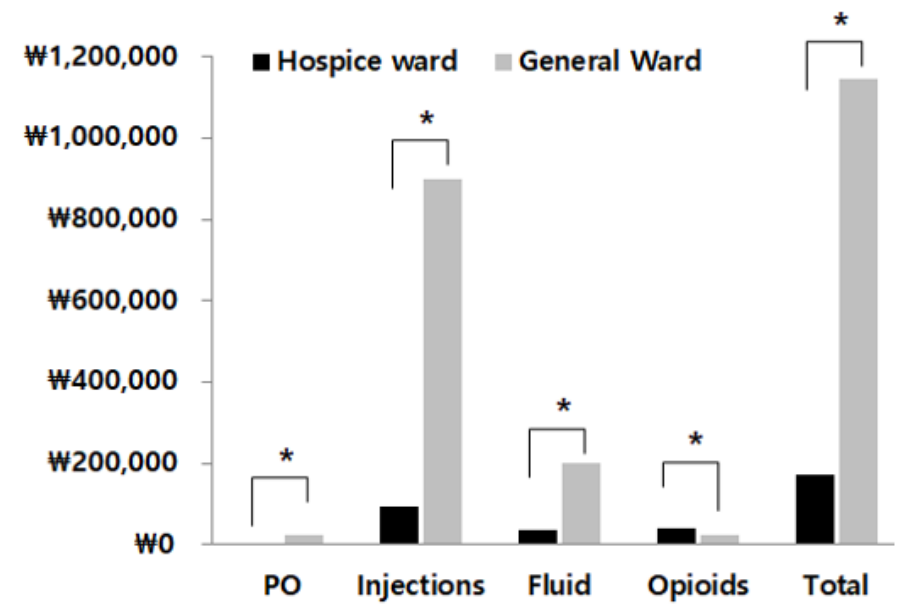

Figure 1

Number and cost of medications used in hospice ward and general ward for 7 days before death. Repeated measures ANOVA *, $p<0.001$.

\section{Hospice ward}

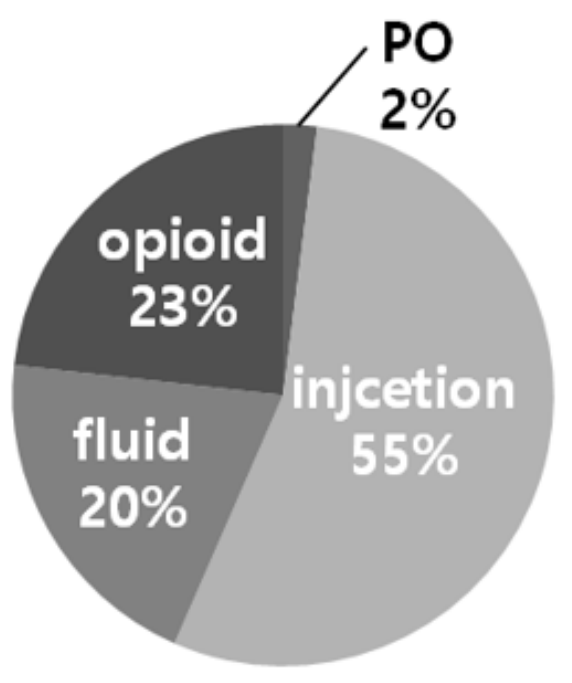

\section{General ward}

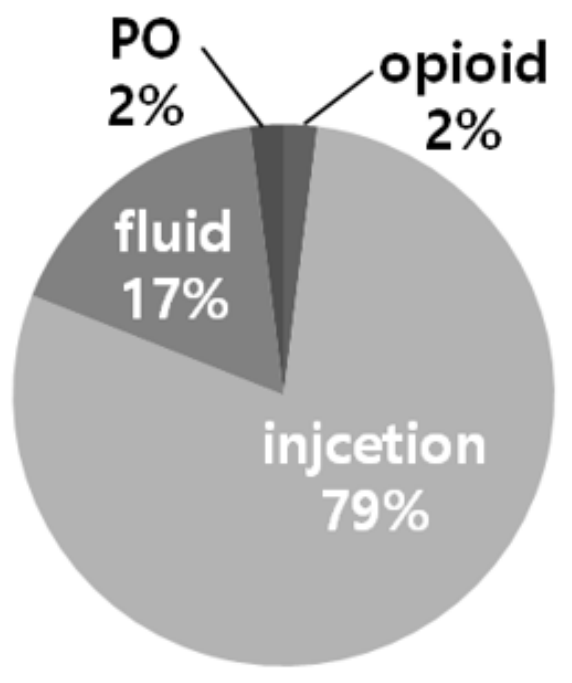

Figure 2

Distribution of medication cost depending on types of drugs used in hospice ward and general ward for 7 days before death. 
Number of medications in Hospice ward

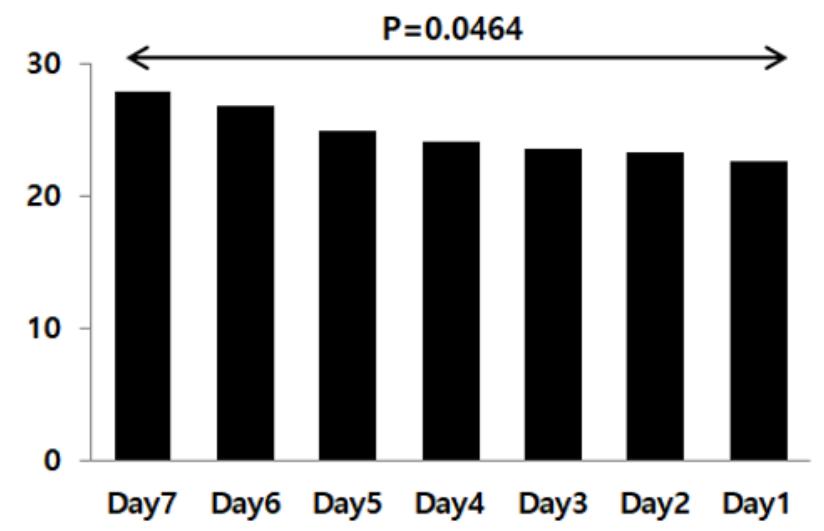

Cost of medications in Hospice ward

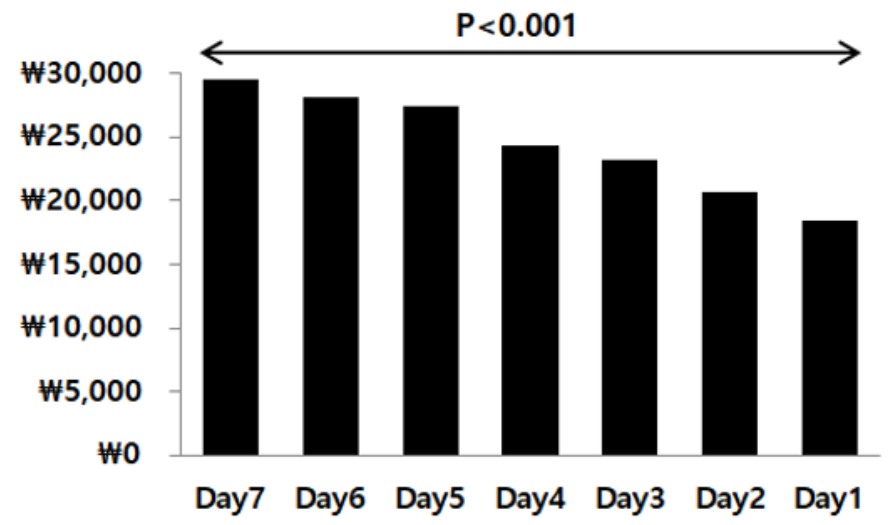

Number of medications in General ward

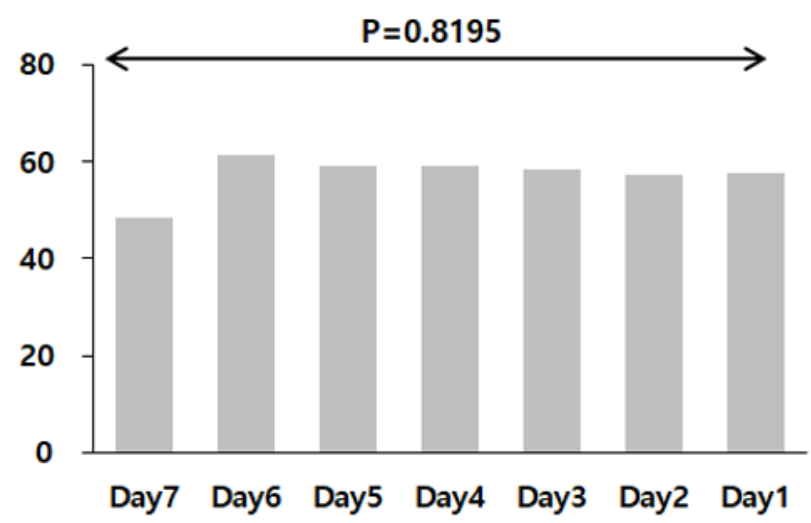

Cost of medications in General ward

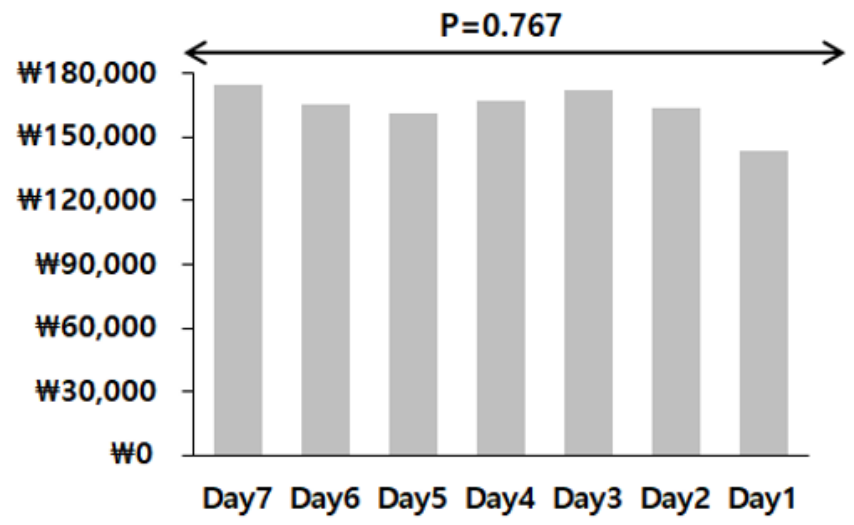

Figure 3

Changes in number and cost of medications used in hospice ward and general ward for 7 days before death. 